\title{
Effects of In-Office and Home Bleaching Gels on the Surface Mercury Levels of Dental Amalgam
}

\author{
Parnian Alizadeh Oskoee ${ }^{a}$ \\ Mahdi Abed Kahnamouib \\ Siavash Savadi Oskoee ${ }^{a}$ \\ Firooz Zadfattahc \\ Fatemeh Pournaghi-Azar ${ }^{d}$
}

\section{ABSTRACT}

Objectives: The aim of this study was to evaluate the effect of different in-office and home bleaching gels on the surface mercury levels of dental amalgam.

Methods: Sixty disk-shaped amalgam specimens (GS-80, SDI- Australia) were prepared and randomly divided into the following treatment groups: 1. Distilled water (control); $2.15 \%$ home-bleach carbamide peroxide (Opalescence PF, Ultra dent, USA) applied for $6 \mathrm{~h} /$ day for 3 weeks; and 3. 35\% in-office bleach carbamide peroxide (Opalescence Quick, Ultradent) applied for $30 \mathrm{~min} /$ week for 3 weeks. Levels of mercury were measured as weight percentages using an energy dispersive x-ray micro-analyzer detector connected to an electron microscope. Data was analyzed using one-way ANOVA and a post hoc Tukey tests $(P<.05)$.

Results: There were no significant differences between the surface mercury levels measured following treatment with the tested home-bleach and in-office bleach products $(P=0.71)$. However, both materials yielded significantly more mercury levels than that of the control group $(\mathrm{P}<.001)$.

Conclusions: The tested bleaching products significantly elevated the surface mercury levels of amalgam in vitro. (Eur J Dent 2010;4:23-27)

Key words: Tooth bleaching; Dental amalgam; Carbamide peroxide; Mercury.

a Associate Professor, Department of Operative Dentistry, Faculty of Dentistry, Tabriz University of Medical Sciences, Tabriz, Iran.

b Assistant Professor, Department of Operative Dentistry, Faculty of Dentistry, Tabriz University of Medical Sciences, Tabriz, Iran.

DDS, Department of Operative Dentistry, Faculty of Dentistry, Tabriz University of Medical Sciences, Tabriz, Iran. d Post graduate student, Department of Operative Dentistry, Faculty of Dentistry, Tabriz University of Medical Sciences, Tabriz, Iran.

- Corresponding author: Dr. Siavash Savadi Oskoee Department of Operative Dentistry, School of Dentistry, Tabriz University of Medical Sciences, Golgasht street, zip 5166614713 Tabriz, Iran. Phone: +989141130160 Fax:+98 4113346977 E-mail: soskoeedahotmail.com 


\section{INTRODUCTION}

Mouthguard bleaching is a popular technique for vital tooth bleaching, ${ }^{1}$ in which either $1.5-10 \%$ hydrogen peroxide or $10-15 \%$ carbamide peroxide are used as bleaching agents. ${ }^{2}$ Recently, bleaching products containing higher concentrations of carbamide peroxide have been introduced for clinical use. Controlled mouthguard bleaching procedure is considered relatively safe with regard to systemic effects. ${ }^{3}$ However; some concerns have been raised about adverse effects of bleaching agents, including irritation of gastric and respiratory mucosa, alteration of the morphology and chemical composition of enamel, dentin and cementum, as well as damage to existing restorations. ${ }^{2,4-7}$

Patients who receive mouthguard bleaching procedures may have amalgam restorations on their existing teeth. ${ }^{8}$ Although bleaching gels are routinely applied to anterior teeth, excessive gel may inadvertently come into contact with amalgam-restored posterior teeth and increase the susceptibility of those amalgam restorations to corrosion and degradation and increase levels of surface mercury. ${ }^{9}$

Several in vitro studies have investigated the effect of different bleaching agents, such as carbamide peroxide, on mercury release from dental amalgam. ${ }^{10,11}$ Rotstein et al assessed the surface levels of mercury and silver of dental amalgam treated with carbamide peroxide using scanning electron microscopy (SEM) and energy-dispersive $X$-ray spectroscopy analysis conducted by means of SEM (EDX). ${ }^{1}$ They demonstrated that consistent treatment with carbamide peroxide solution might cause micro structural changes in amalgam surface, possibly increasing the levels of surface mercury and silver. ${ }^{1}$ Mercury released from dental amalgam during mouthguard bleach- ing can be absorbed by the oral mucosa, as well as by the respiratory and gastrointestinal tracts, thus increasing the total body burden of mercury, and leading to a variety of systemic toxic effects. ${ }^{12}$ The possible detrimental interactions between these alloys and the bleaching agents might be of clinical significance. ${ }^{8}$ Clinicians must take special care to reduce the release of mercury when using bleaching agents.

Considering the issues discussed above and the increasingly high public demand for home and in-office bleaching, the aim of the present study was to evaluate the levels of surface mercury in amalgam specimens treated intermittently with two types of home and in-office bleaching gels using SEM-EDX. The null hypothesis stated that the intermittent application of these two bleaching agents has no effect on surface mercury levels of amalgam restorations.

\section{MATERIALS AND METHODS}

Table 1 shows the particulars of the materials used. Sixty specimens of amalgam (GS-80, SDI- Australial were prepared. Trituration was carried out by a dental amalgamator (Duomat 2, Degussa, Germanyl according to manufacturer's instructions. The freshly prepared mix was then condensed vertically and laterally into molds 2 $\mathrm{mm}$ deep and $5 \mathrm{~mm}$ in diameter with the use of flat-faced round hand condenser. The thickness of each increment was $1 \mathrm{~mm}$ to ensure maximum condensation effectiveness. All the steps were carried out by one operator. After burnishing the specimens were left in the mold for 60 minutes for initial setting. Then one surface from each specimen was coated with nail varnish. Subsequently, the specimens were removed from the molds and stored in $37^{\circ} \mathrm{C}$ distilled water. Forty-eight hours later, the uncoated surfaces of the specimens

Table 1. The materials used in the study.

\begin{tabular}{l|c|c|c}
\hline Materials & Product name & Manufacturer & Chemical composition \\
\hline Amalgam & GS-80 & SDI, Australia & $\begin{array}{c}\text { Capsulated, admix, non gamma2, } \\
\text { high-copper, 600 mg alloy+540 mg } \\
\text { mercury in each capsule }\end{array}$ \\
\hline Carbamide peroxide 15\% & Opalescence PF & $\begin{array}{c}\text { Ultradent Inc., South } \\
\text { Jordan, USA }\end{array}$ & $\begin{array}{c}0.11 \% \text { Flouride ion + 0.5\% Potassium } \\
\text { nitrate }\end{array}$ \\
\hline Carbamide peroxide 35\% & $\begin{array}{r}\text { Opalescence } \\
\text { Quick }\end{array}$ & $\begin{array}{c}\text { Ultradent Inc., South } \\
\text { Jordan, USA }\end{array}$ & Carbamide peroxide 35\% \\
\hline
\end{tabular}


were smoothed with polishing rubber disks (Polisher, RA Kendu, Liechtenstein) that mounted on a slow-speed contra-angle handpiece under water coolant. Then the specimens were rinsed with $20 \mathrm{ml}$ of distilled water and randomly divided into three groups of 20 specimens each. In the control group the specimens were stored in $37^{\circ} \mathrm{C}$ distilled water for three weeks. The other two experimental groups (home and in-office bleaching) were prepared as follows:

For home bleaching group the specimens were treated with $0.1 \mathrm{ml}$ of $15 \%$ carbamide peroxide (Opalescence PF, Ultradent, South Jordan, USA) applied six hours a day for three weeks, during which the specimens were placed in a wet incubator at $37^{\circ} \mathrm{C}$. At each time interval, the amalgam specimens were rinsed with $20 \mathrm{ml}$ of distilled water and restored in $37^{\circ} \mathrm{C}$ distilled water.

The specimens in the in-office group were treated in the same manner as in the home bleaching group but in this group, 35\% carbamide peroxide gel (Opalescence Quick, Ultradent, South Jordan, USA) was used. The specimens were treated with $0.1 \mathrm{ml}$ of the gel 30 minutes a day for three weeks. After three weeks all the specimens were rinsed with distilled water and dried. Each specimen was then prepared for scanning electron microscopy and surface mercury level measurement. The treated specimens were mounted on aluminum stubs and coated with $200 \AA$ layers of gold in a coating device (E 5200 Auto sputter, England). The level of surface mercury in each specimen was measured with SEM (Cam Scan, MV2300, USA) and EDX (Link, Oxford, U.K). Each specimen was irradiated at two additional equidistant areas at the center at a voltage of $25 \mathrm{KV}$ for 120 seconds. The quantitative analysis of the percentage of weight concentration of the surface mercury was performed by applying the computerized Z.A.F (Z = atomic number, $A=$ absorption, $F=$ fluorescence) correction method. ${ }^{1}$ For each specimen the mean value of two areas was obtained. One-way analysis of variance (ANOVA) was used to compare surface levels of mercury between the groups. A post hoc Tukey test was used for the two-by-two comparison of the groups $(P<.05)$. The specimens were also observed for surface morphologic changes with the MV 2300 scanning electron microscope.

\section{RESULTS}

The levels of surface mercury in study groups are shown in Table 2. The control group had the lowest level of surface mercury and the home bleaching group demonstrated the highest values. Results of one-way analysis of variance (ANOVA) revealed that there were significant differences in the mean values of mercury weight percentages between the groups $(P<.001)$. Post hoc Tukey test did not demonstrate any significant differences between the home bleaching and in-office bleaching groups $(P=0.71)$, but according to this test the levels of mercury detected in the home bleaching and in-office bleaching groups were significantly higher than those in the control group $(P<.001)$. In scanning electron micrographs morphologic changes were observed on the surface of the specimens in the $15 \%$ and $35 \%$ carbamide peroxide groups in comparison with the control group (Figure 1).

\section{DISCUSSION}

Recently, attention has been focused on mercury release from amalgam in the oral cavity and its potential detrimental effects. ${ }^{13}$ Dental amalgam is a complex metallic biomaterial consisting of as many as 8 to 10 distinct phases with different micro structural features. ${ }^{1}$ Amalgam may be susceptible to strong oxidative action of bleaching agents. ${ }^{13}$ Contrary to the results of a study by $\mathrm{Al}$ Salehi et $a l,{ }^{14}$ results of the present study demonstrated that intermittent treatment of amalgam specimens with both home and in-office bleaching agents increases the surface levels of mercury. Hydrogen peroxide is the active ingredient in bleaching agents. ${ }^{15}$ Carbamide peroxide can be decomposed; yielding one-third of hydrogen per-

Table 2. Means of surface amalgam levels (weight percentages) in each group.

\begin{tabular}{lcccc}
\hline Groups & Mean & SD & Maximum & Minimum \\
\hline Control & 36.11 & 3.13 & 39.10 & 29.00 \\
Home bleaching & 42.32 & 2.00 & 47.20 & 38.70 \\
In-office bleaching & 41.69 & 1.87 & 45.70 & 38.80 \\
\hline
\end{tabular}


oxide and two-thirds of urea. ${ }^{15}$ Hydrogen peroxide decomposes and produces free radicals $\mathrm{OH}^{-}$and 0 . Perhydroxil $\left(\mathrm{OH}^{-}\right)$is a strong oxidizing agent, ${ }^{15}$ which can cause changes in the surface levels of the amalgam metallic components, and expose the silver-mercury matrix which is a potential source for mercury release. ${ }^{1}$ Certosimo et $\mathrm{al}^{13}$ and Rotstein et $\mathrm{al}^{2}$ demonstrated that the level of mercury release is related to the concentration of peroxide agent, i.e. as peroxide concentration increases so does the potential for oxidation, corrosion, and dissolution of the amalgam. ${ }^{13}$ Therefore, it is expected that surface mercury levels of amalgam treated with $35 \%$ carbamide peroxide will be high. It should be noted that there was a significant increase in the levels of surface mercury in $15 \%$ carbamide peroxide group compared to the control group and a slight increase compared to that in the $35 \%$ carbamide peroxide group. Longer exposure time of specimens treated with $15 \%$ carbamide peroxide (six hours a day for three weeks) compared to that of $35 \%$ carbamide peroxide (30 minutes a day for three weeks) may compensate for lower peroxide concentrations. This is consistent with the results of studies carried out by Robertello et al, ${ }^{13,16}$ Rotstein et al, ${ }^{1,12}$ Ahn et $\mathrm{al}^{17}$ and Okabe et al, ${ }^{11}$ who demonstrated that the extent of oxidation, corrosion, micro structural changes, and dissolution of the amalgam surface

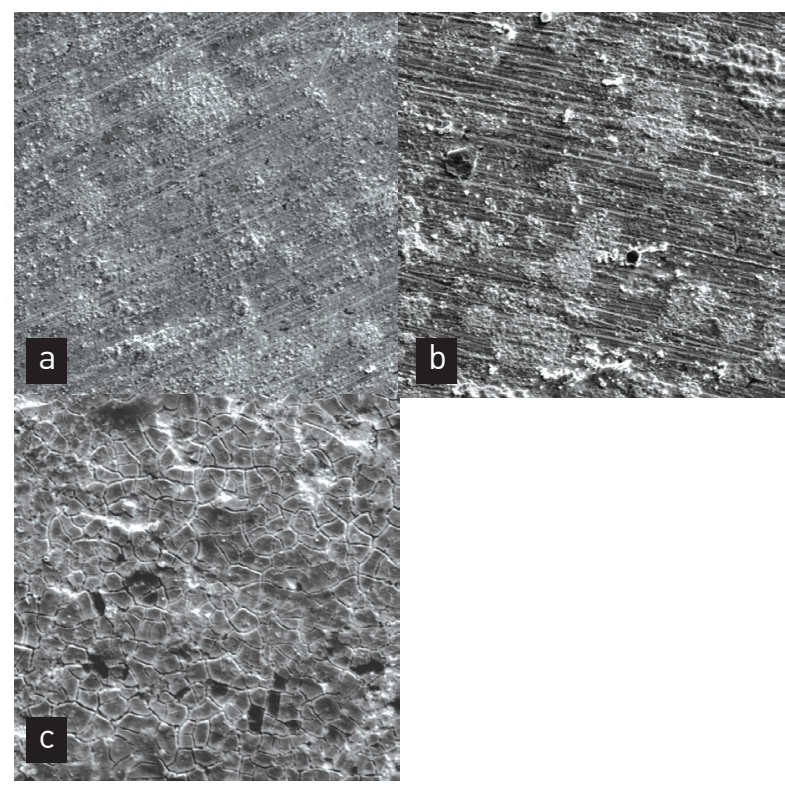

Figure 1. Electron micrographs: a. Pattern of amalgam surface in the control group; b. Disruption of the pattern in the $35 \%$ carbamide peroxide group and exposure of some parts of the surface layer; c. Sever changes on the surface layer seen as crack formation in the $15 \%$ carbamide peroxide group (Original magnification, $\mathrm{x} 500$ ). are dependent upon the duration of amalgam surface exposure to peroxide.

Our results demonstrated higher levels of surface mercury in amalgam specimens treated intermittently with both home and in-office bleaching gels in comparison to the control group; however, considering the dental biofilm effect on reducing mercury release into the surrounding environments $^{18}$ it should be noted that the higher mercury levels found with SEM-EDX technique do not necessarily indicate their presence in saliva or absorption by the oral tissues. Nonetheless, the cause-and-effect relationship between different bleaching agents and amalgam tissue toxicity, and the effect of concentration and exposure duration of oxidizing agents require further investigations in vivo.

\section{CONCLUSIONS}

Within the limitations of this study it can be concluded that surface levels of mercury are higher in intermittently bleached amalgam compared with untreated amalgam.

\section{REFERENCES}

1. Rotstein I, Mor C, Arwaz J R. Changes in surface levels of mercury, silver, tin and copper of dental amalgam treated with carbamide peroxide and hydrogen peroxide in vitro. Oral Surg Oral Med Oral Pathol Oral Radiol Endod 1997;83:506-509.

2. Rotstein I, Dogan H, Avron Y, Shemesh H, Mor C, Steinberg D. Protective effect of copalite surface coating on mercury release from dental amalgam following treatment with carbamide peroxide. Endod Dent Tramatol 2000;16:107-110.

3. Haywood VB, Robinson FG. Vital tooth bleaching with night guard vital bleaching. Curr Opin Cosmet Dent 1997;4:45-52.

4. Yarborough DK. The safety and efficacy of tooth bleaching: a review of the literature 1988-1990. Compend Contin Educ Dent 1991;12:191-196.

5. Redmond AF, Cherry DV, Bowers DE Jr. Acute illness and recovery in adult female rats following ingestion of a tooth whitener containing 6\% hydrogen peroxide. Am J Dent 1997;10:268-271

6. Zalkind M, Arwaz Jr, Goldman A, Rotstein I. Surface morphology changes in human enamel, dentin and cementum following bleaching: a scanning electron microscopy study. Endod Dent Traumatol 1996;12:82-88.

7. Bailey SJ, Swift EJ. Effects of home bleaching products on composite resins. Quintessence Int 1992;23:489-494. 
8. Canay S, Cehreli MC, Bilgic S. Invitro evaluation of the effect of a current bleaching agent on the electrochemical corrosion of dental alloys. J Oral Rehabil 2002;29:10141019.

9. Rotstein I, Dogan H, Avron Y, Shemesh H, Steinberg D. Mercury release from dental amalgam after treatment with 10\% carbamide peroxide in vitro. Oral Surg Oral Med Oral Pathol Oral Radiol Endod 2000;89:216-219.

10. Hummert TW, Osborne JW, Norling BK, Cardenas HL. Mercury in solution following exposure of various amalgam to carbamide peroxides. Am J Dent 1993;6:305-309.

11. Okabe T, Ferracane J, Cooper C, Matsumoto H, Wagner M. Dissolution of mercury from amalgam into saline solution. J Dent Res 1987;66:33-37.

12. Rotstein I, Avron Y, Shemesh H, Dogan H, Mor C, Steinberg D. Factors affecting mercury release from dental amalgam exposed to carbamide peroxide bleaching agent. Am J Dent 2004;17:347-350.

13. Certosimo A, Robertello F, Dishman M, Bogacki R, Wexel $M$. The effect of bleaching agents on mercury release from spherical dental amalgam. Gen Dent 2003;51:356-359.

14. Al- Salehi SK, Hatton PV, Miller CA, Mcleod C, Joiner A. The effect of carbamide peroxide treatment on metal ion release from dental amalgam. Dent Mater 2006;22: 948953.

15. Fasanaro TS. Bleaching teeth: History, chemicals and methods used for common tooth discoloration. $J$ Esthet Dent 1992;4:71-78.

16. Robertello FJ, Dishman MV, Sarrett DC, Epperly AC. Effect of home bleaching products on mercury release from an admixed amalgam. Am J Dent 1999;12:227-230.

17. Ahn HJ, Song KB, Lee YE, Lee JT, Cho SA, Kim KH. Surface change of dental amalgam after treatment with $10 \%$ carbamide peroxide. Dent Mater 2006;25:303-308.

18. Steinberg D, Blank O, Rotstein I. Influence of dental biofilm on release of mercury from amalgam exposed to carbamide peroxide. J Biomed Mater Res B Appl Biomater 2003;67:627-631. 